\title{
المشكلات المنهجية في تعليم اللغة العربية للناطقين بغيرها بإندونيسيا
}

\author{
M. Ilham Muchtar
}

Universitas Muhammadiyah Makassar, Sulawesi Selatan, Indonesia

*E-mail:ilhammuchtar@unismuh.ac.id

الملخص. لا يز ال تعليم اللغة العربية يو اجه العديد من المشاكل. مصدر المشكلة هو الاعتماد

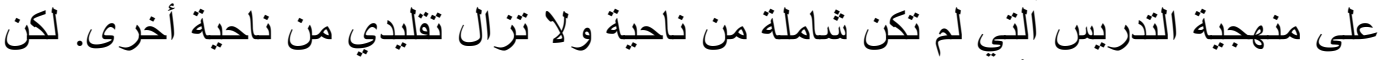

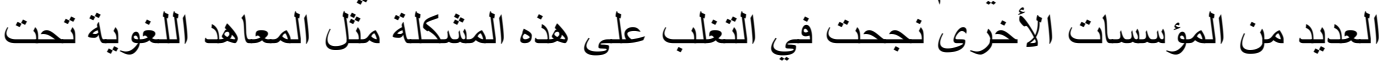

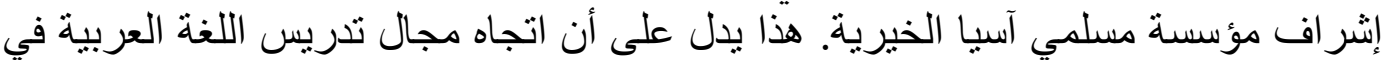

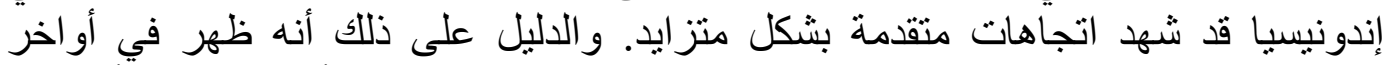

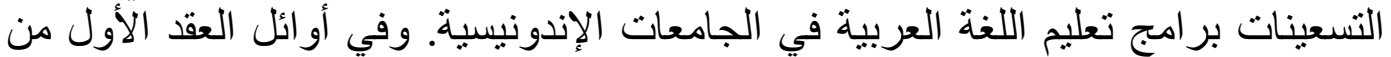

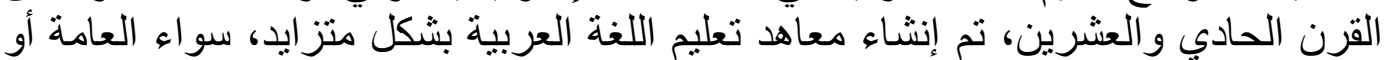

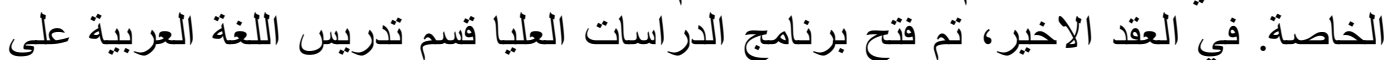

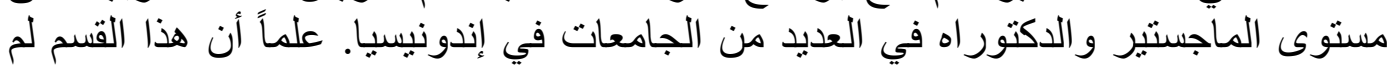
يكن موجود في السابق إلا في المستوى البيز في البلوريوس.

الكلمات المفتاحية: التدريس ، المشكلات ، التعليم ، اللغة ، التركيز

Abstrak. Pengajaran bahasa Arab masib menghadapi banyak problema. Muara dari problematika tersebut adalah pada ketergantungan terhadap metodologi pengajaran yang belum komprehensif dan masih taqlidi. Tetapi beberapa lembaga lain sudab berbasil mengatasi problematika ini seperti ma'bad-ma'bad binaan Asia Muslim Charity Foundation. Hal ini menunjukkean orientasi bidang pengajaran bahasa Arab di Indonesia sudah mengalami tren semakin maju. Indikasinya adalah pada akbir tabun 90-an muncul di perguruan tinggi Indonesia program pengajaran bahasa Arab intensif. Kemudian, pada awal tabun 2000-an, institut pengajaran bahasa Arab semakin banyak didirikan, baik negeri maupun swasta. Babkan dalam satu dekade terakbir, program pascasarjana konsentrasi pengajaran bahasa Arab telah dibuka pada tingkat magister dan doktor di beberapa perguruan tinggi di Indonesia. Di mana sebelumnya banya ada pada jenjang strata satu.

Kata Kunci: Pengajaran, Problematika, Pendidikan, Bahasa, Konsentrasi 
المعاهد. فيحاول هذا المقال المتواضع تسليط التمهيّ

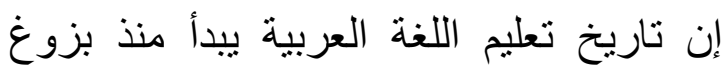

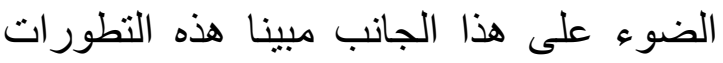
شمس الإسلام في هذه البلاد باعتبار أن تعلمها

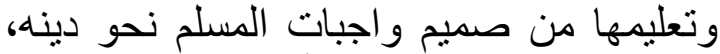

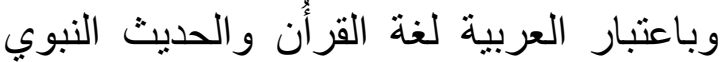

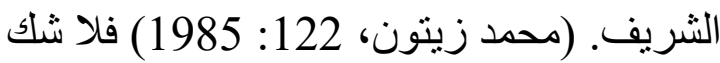

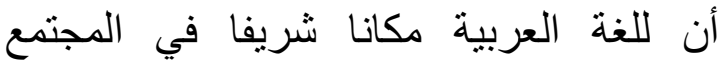

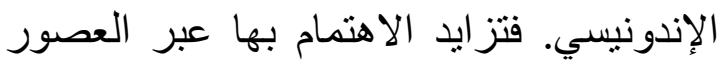

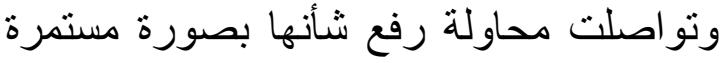

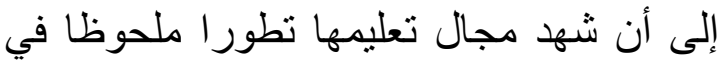

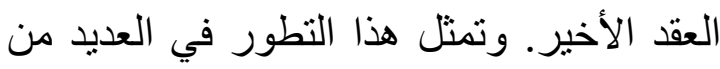
الجوانب أهمها الجانب الإداري، و والدنهج،

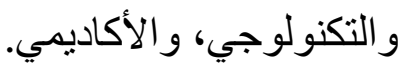
إلا أن هذا المكان العظيم للغة العربية والاهتمام

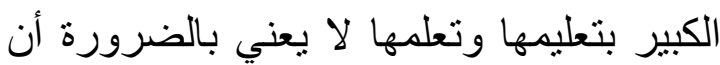
هذه اللغة قد حظيث ما تستحقه كلغة دئنة دينية

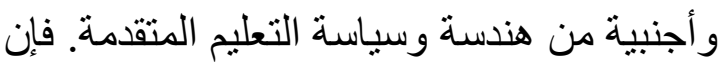
الوضع الآني لمجال تعليم اللغة العربية في

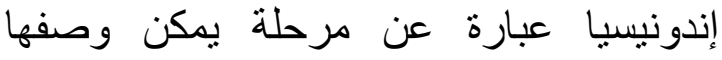

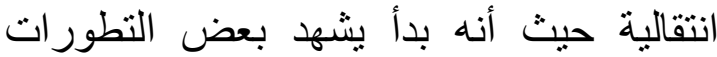

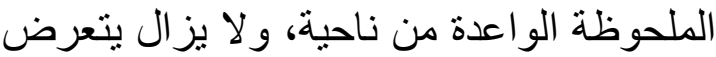
لعدة مشاكل شائكة من ناحية أخرى. (رسمان، (2012:3 من الملاحظ أن تعليم اللغة العربية في معظم

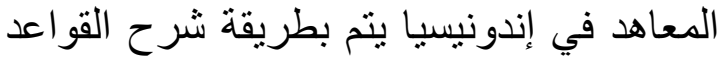
وترجمة النصوص إلى النى اللغة الإندونيسية، بالإضافة إلى أن نظام التقويم المتبع لقياس

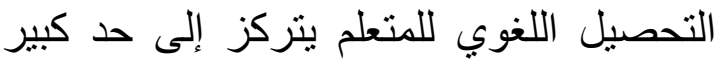
على اختبارات جوانب المعرفة اللغوية وقد لا لا لإنير

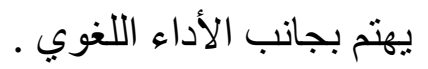
تعليم اللغة العربية على مثل هذا الأسلوب هو الإن تقليدي الإتجاه فيضطر إلى تغييره وتطويره،

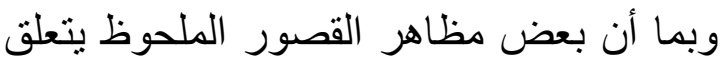

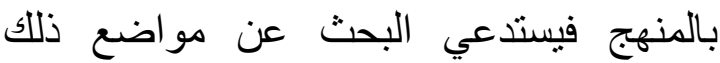
القصور في منهج تعليم اللغة العربية في العيع

\section{تعليم اللغة العربية في إندونيسيا من حيث الأهداف التربوية} إن من العوامل الرئيسية المؤدية إلى انتشار

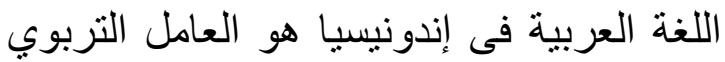

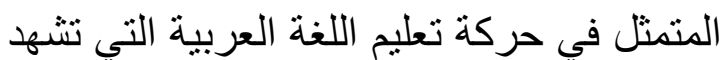
تطورًا واضحاً حينا بعد حين. تتركز الأهداف فئن التربوية في تعليم اللغة العربية في نقاطيها

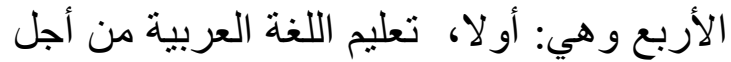

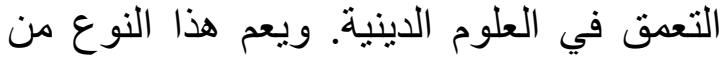

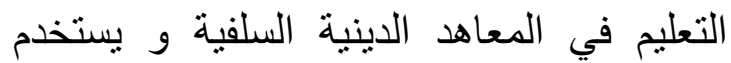
طريقة النحو و الترجمة. ثانياً، تعليم اللغة النة العربية للاغراض التأهيلية و المهنية. و يتم تعليم اللغة العربية على هذا النوع في قلى لئه تدريس اللغة العربية بالجامعات. ثالثاً، تعليم اللغة العربية لأغر اض خاصة، للاضلة مثل تعليم اللغة

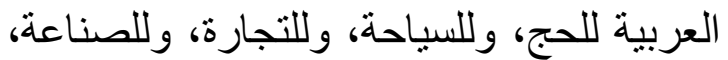
وللعمال الإندونيسيين العاملين في بلاد العرب. ورابعاً، تعليم اللغة العربية الهادف إلى تلى تلزويد العادين الطلاب بالمهار ات اللغوية خاصة دهارة التعبير

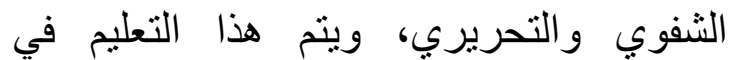
المعاهد اللغوية العصرية ـو وأخص بالذكر هنا

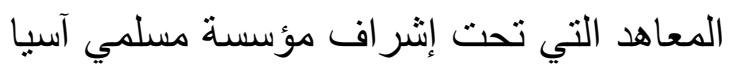

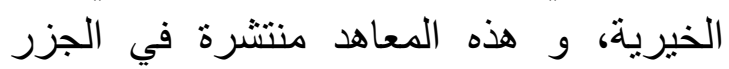

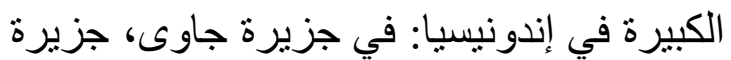

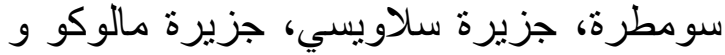
فى جزيرة كالمنتان (عبد القهار زينال، 19: (.2017

التطورات التي مر بها تعليم اللغة العربية في تي

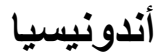
وبما أن اللغة العربية لغة دينية جاءت متزامنة مع دخول الإسلام في إندونيسيا فلها مكانة فئة فئنة مرموقة في حياة شعبها. إلا أن التطور في تعليم 
اللغة العربية يكون في بداية الألفينات، حيث تنشأ في إندونيسيا معاهد لتعليم اللغة العربية

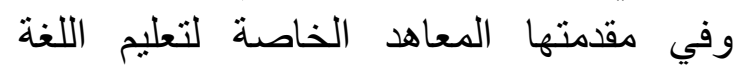
العربية والدراسات الإسلامية (مصطفى محمد مداهية نوري، 392: 2013). وثمة مؤشرات كثيرة تدل على ذلك ويتلخص أبرز ها فيما يلي: أو لا: ظهور بر امج تعليم اللغة العربية المكثفة في الجامعات لات فعوري

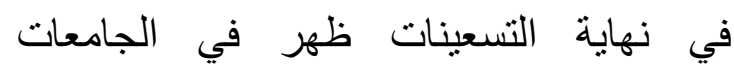
الإسلامية الإندونيسية حكومية كانت أم أهلية ما فالية فئات يعرف ببر امج تعليم اللغة العربية المكثفة. وهي الإني بر امج يجب أن يمر بها الطلاب الجدد في السنة الأولى من دراستهم وتهذف إلى تزويدهم بالمهار ات اللغوية التي تساعدهم في دراستهم الجامعية. وجاءت فكرة إدارة هذه البر امج تذليلا

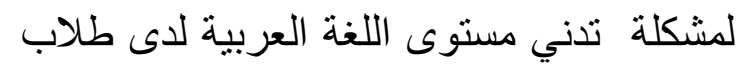

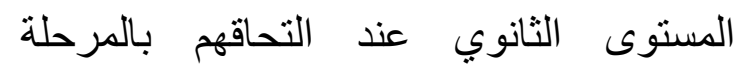
الجامعية مما يؤدي بهم إلى التعرض لفي لمشاكل

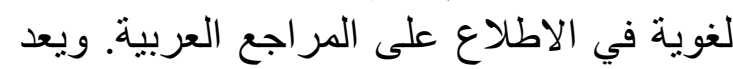

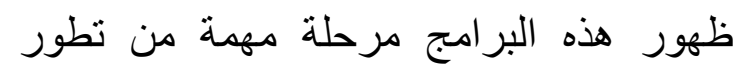
مجال تعليم اللغة العربية في إندونيسيا وذلك دهد

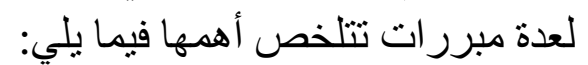

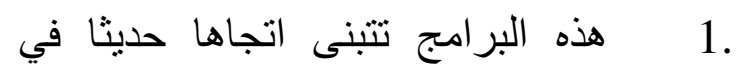
تعليم اللغة العربية متخليا عن اتجاه النحو والترجمة الذي شاع الاستناد إليه في تعليم اللغة العربية بإندو نيسيا. 2.

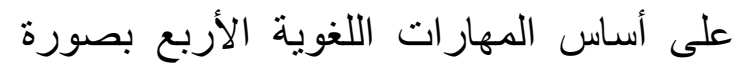
متكاملة بخلاف نظيرتها السابقة التي كانت

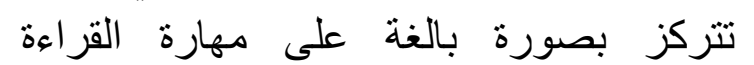
و الترجمة.

3. البرامج من أحدث سلسلة تعليم اللغة العربية

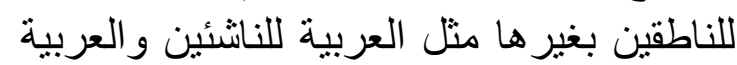
بين يديك. وهذا بخلاف المواد التعليمية القديمة الثائعة التي تستمد من الكتب الدينية واللغوية
وغير ها من الكتب التي لم يكن إعدادها لأهداف تعليمبة.

4.

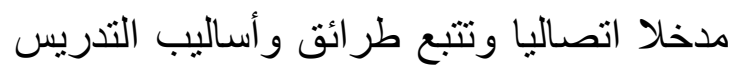

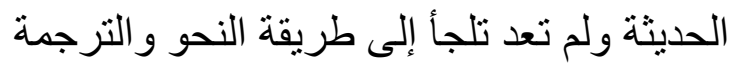
التي ساد استخدامها من قبل. 5 . 5 تستعين عملية التعليم في هذه البرامج بأنو اع مختلفة من الوسائل التعليمية الحديثة مثل فئل فئل الكمبيوتر والمختبر اللغوي وجهاز التسجيل التيل والقمر الصناعي وغير ها من الوسائل الحديثة التي لم تشع استخدامها التعليمي من قبل.

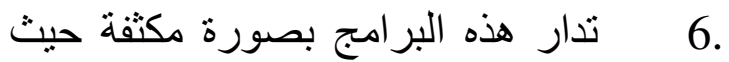
تستنفد الدراسة من ثلاثة إلى خمسة أيام في

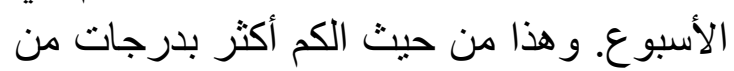
عدد الحصص في البرامج العادية التي تستغرق حصة واحدة فقط (مدة ساعة ونصف الساعة)

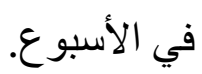

7. بتوفير بيئة لغوية وذللك ببناء داخلية الطلاب البرج

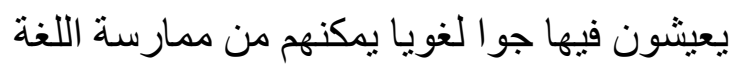
العربية في حياتهم اليومية. وهذا يعد تطورا غير مسبوق إذ إن انعدام البيئة اللغوية مشكلة التهاية تجابه أغليية المؤسسات التربوية في إندونيسيا

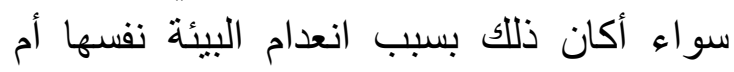
بسبب انعدام من يحركها ويشرف عليها.

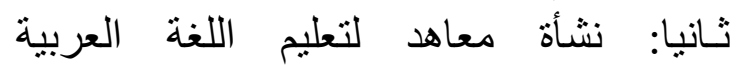
و الدر اسات الإسلامية: تئة فياه نشأت في بداية الألفينات معاهد لتعليم اللغة الإنة

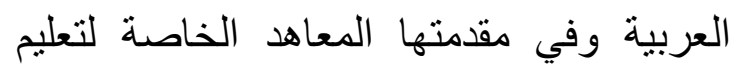
اللغة العربية والدر اسات الإسلامية. وتعد نشأية المدأية هذه المعاهد من أهم مؤشرات تطور مجال تعليم

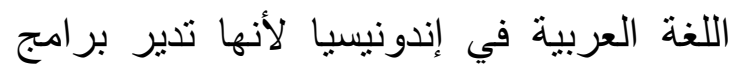
تعليم اللغة العربية في ضوء الاتجاهات الحئ الخديثة

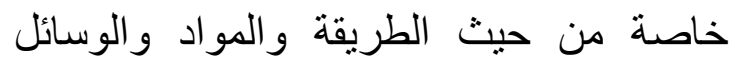
التعليمية. 
إضافة إلى ذلك فان هذه المعاهد مهدت طريقا إلى إدارة برامج حديثة لتعليم اللغة العربية

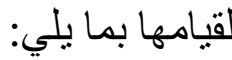
1 . 1 إنها توظف المعلمين المؤهلين معرفيا ومِهَنيّا في مجال تعليم اللغة العربية للناطقين بغيرها المبعوثين من الدول الناطقة بالعربية مثل السودان. إنها لا تزود الطلاب بالمهار ات اللغوية 2.

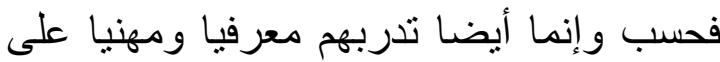
تعليم اللغة العربية. إنها توفر بيئة لغوية من خلال توفير داخلية الطلاب التي تمكن المعهد من الإشراف

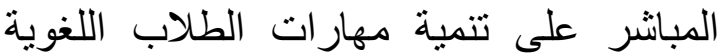
و التي توفر للطلاب في الوقت نفسه جو التوات خاصا يعيشون فيه حياتهم اليومية باللغة العربية.

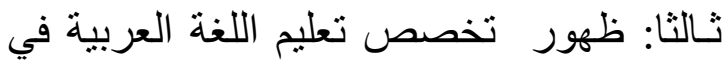

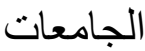
ظهر في السنوات العشر الأخيرة تخصص تعليم الإنيم اللغة العربية في بعض الجامعات الإسلامية الإنية

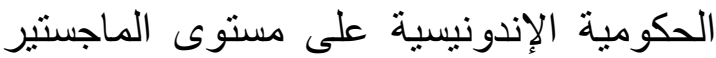

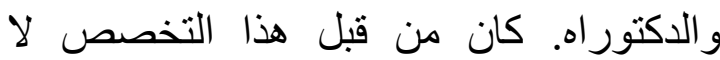

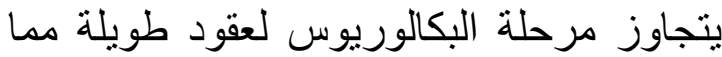
يقف وراء تدني المؤهل التعليمي لأغلبية معلمي

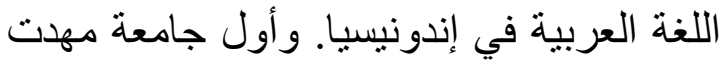

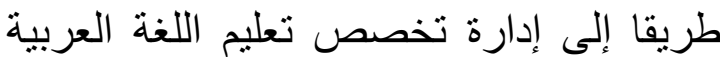
هي الجامعة الإسلامية الحكومية مالانج وهي الإني

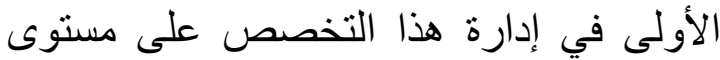
الماجستير والوحيدة على مستوى الأكتوراه (عبد القهار زينال، 31: 2017) وهذا التطور الأكاديمي رغم أنه حديث العهد يشكل بكل التأكيد مشهدا من مشاهد نطور مجال النهال تعليم اللغة العربية في إندونيسيا لأنه يعكس تغير سياسة تحسين مجال تعليم اللغة العربية من لالنية سياسة منهجية مجردة إلى سياسة أثنمل تراعي الئي المنهج و المو ارد البشرية على السواء.
إضافة إلى ذلك يقدم هذا التطور حلا يستحق التقدير لتذليل مشكلة قلة عدد المعلمين المؤهلين

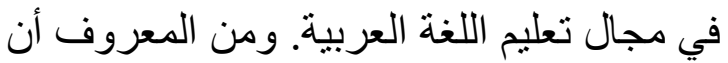
قلة عدد المعلمين المؤهلين ليست لقلة العيدة المعنيين

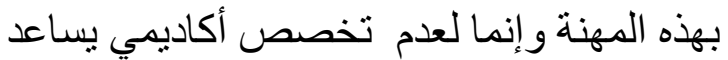

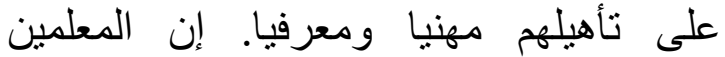
المؤهلين الذين يحملون شهادة الماجستير و الدكتور اه هم خريجو جامعات الثرق الأوسط وعددهم حتى الآن لم يتعد أصابع اليدين لأن النان التكلفة المالية للاراسة في الدان لأدئ العربية كبيرة

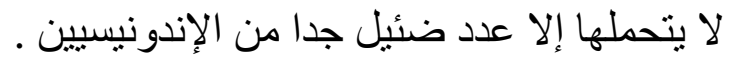
ولعل آخر ما أنجزته الجامعات الإندونيسية من الإندانين

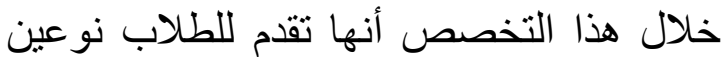

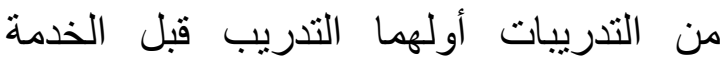
والآخر التدريب أثناء الخدمة. يخص الأول

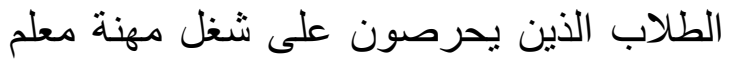
اللغة العربية بعد تخرجهم من الجامعة. أما الثاني فيخص معلمي اللغة العربية الر اغبين في التئية رفع مستواهم التعليمي أو مؤهلاتهم المهنية. و هذا يفيد مجال تعليم اللغة العربية ليس فقط في النياتي

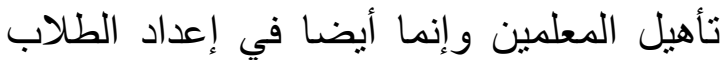

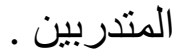
رابعا: ظهور برامج تعليم اللغة العربية لأغر اض خاصة: ناضعة ظهر في السنوات الأخيرة برامج تعليم اللغة العربية لأغر اض خاصة مثل تعليم اللغة العربية

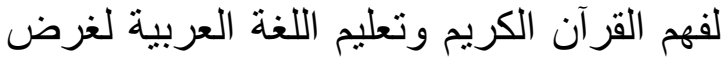

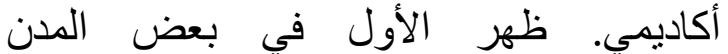
الإندونيسية مثل جاكارتا وسور ابايا ومالانج ويتخذ مكانه في المساجد ومراكز النشانداطنات وستان الإسلامية ويخص الراغبين في فهم القرآن

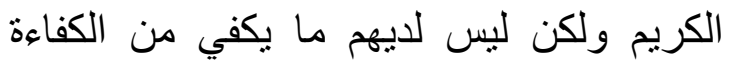

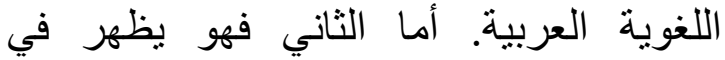
الجامعات ويخص الطلاب المتخصصين في في في العلوم الإسلامية الراغبين في رفع مستواهم 
اللغوي لكي يتمكنوا من الاطلاع على المراجع

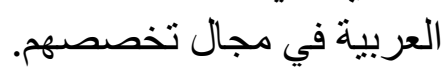
وظهور هذه البرامج التعليمية يعد تطورا في في لئي مجال تعليم اللغة العربية وذلك لثناثلة أسباب:

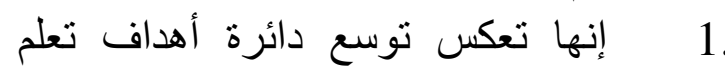

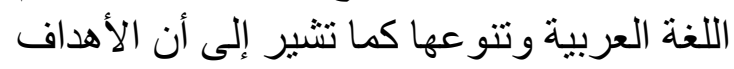

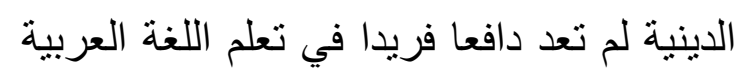
لدى الإندونيسبين. 2 إنها تدل على رغبة متز ايدة ومتباينة 2. لاى الإندونيسيين في تعلم اللغة العربية حيث التيث

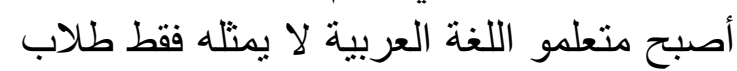

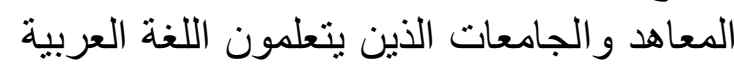

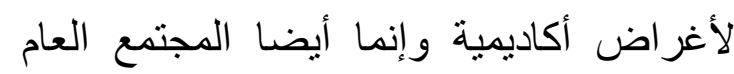

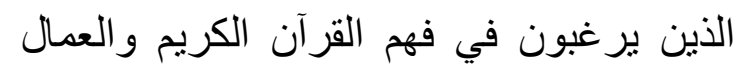
الذين يريدون أن يعملوا في الدول العربية.

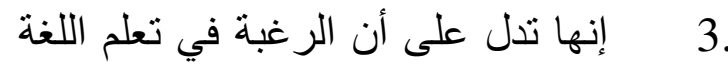

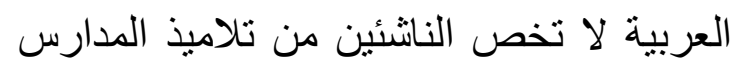

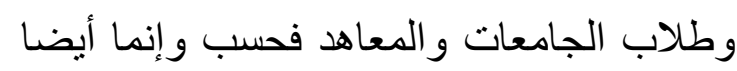

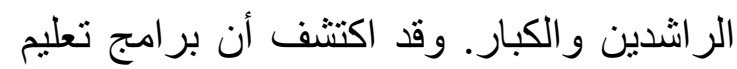
اللغة العربية لفهم القرآن الكريم في إندونيسيا

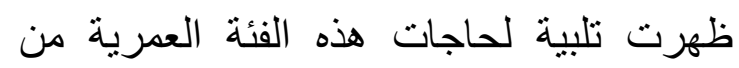

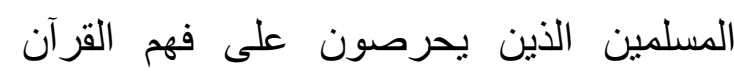
الكريم ولم يسبق لهم تعلم اللغة العربية.

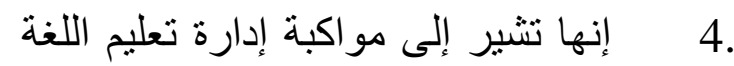
العربية اتجاهات حديثة في تعليم اللغة الأجنبية

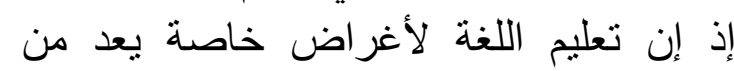
التطورات الأخيرة في مجال تعليم اللغات لأند الأجنبية. 5 5 5 إنها يدل على تطور مجال بناء مناهج تعليم اللغة العربية للإندونيسيين لأن طهور بناه

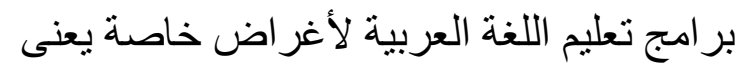
بالضرورة بناء منهج جديد لتعليم اللغة العربية.

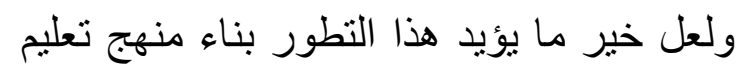

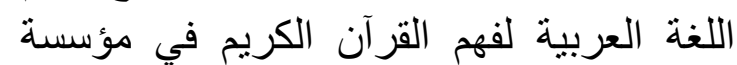

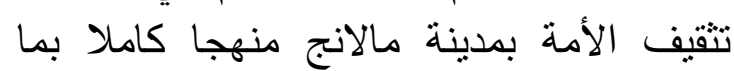
يكونه من أهداف ومحتوى وطريقة وتقويم.
خامسا: تعليم اللغة العربية من خلال الوسائل

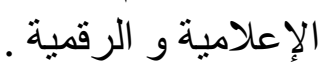

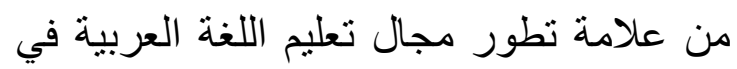

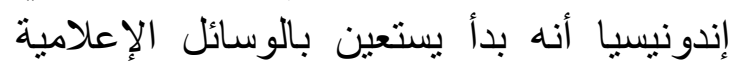

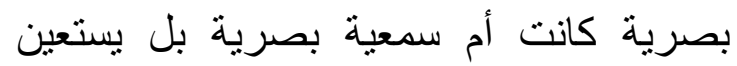
بأحدث نوع من هذه الوسائل و هي الونة الوسائل

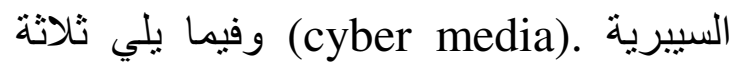
أهم أنواع الوسائل الإعلامية و الرقمية التي من فئ

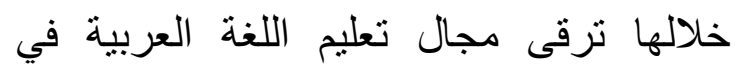
إندونيسيا : ترفي

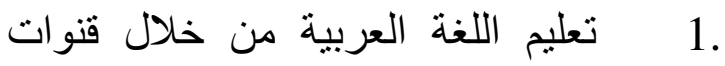
التلفزيون. هناك قانتا تلفزيون سبق أن الن بثنا

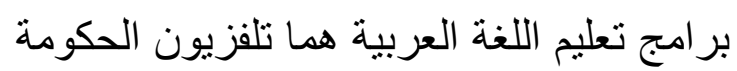

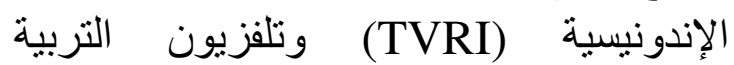

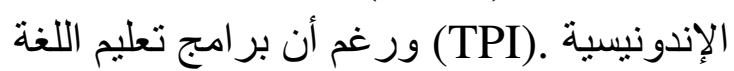

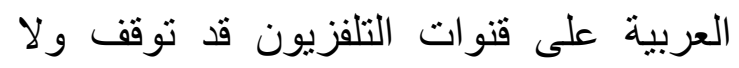

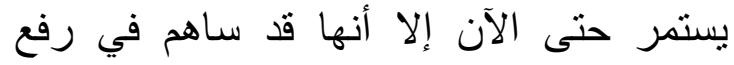
مستوى تعليم اللغة العربية أدناه في تعريف هذئ فئه

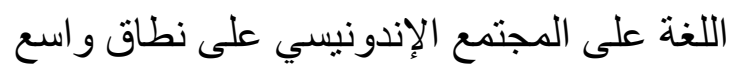

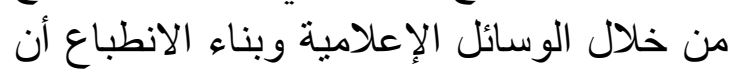
هذه اللغة لا تقل أهية من اللغات الأجنيبة الأخرى. لكن في السنوات الأخيرة أنشئت الأنئ

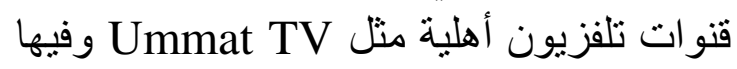
بر امج متسلسلة في تعليم اللغة العربية. 2. و المجلة التي تئدي هذه المهيمة هي المجلة المبلة العربية الثهرية الصادرة في مدينة سمار انج النجان "آلو إندونيسيا "Indonesia Hallo تفرد صفحة لتعليم اللغة العربية خاصة التية المفردات، والمجلة الثهرية العربية الصادرة في مدينة مالانج "نادي " Nadi

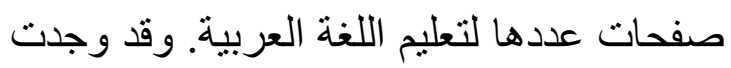

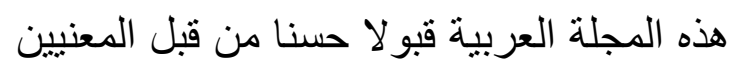
باللغة العربية وفي مقدمتهم طلاب المبان المعاهد والجامعات لأنهم يستقيدون منها في في تحسين

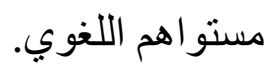


3. الإنترنت وفي الوسائط الإجتماعية أو الوسائل

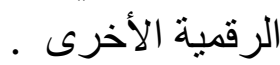

إن استخدام هذه الوسائل الإعلامية والرقية الرمية

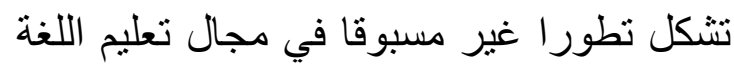

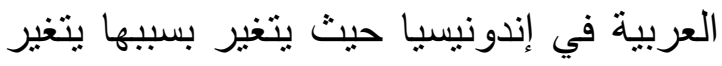

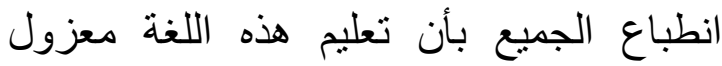

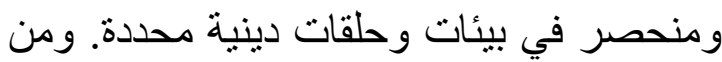

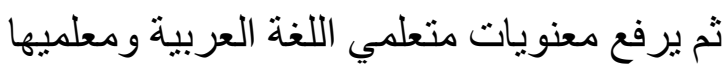
سيكولوجيا. بعض المشكلات التربوية القائمة

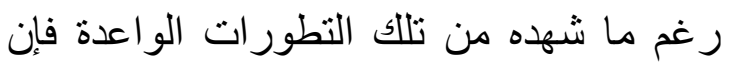

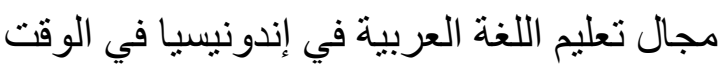
نفسه ما زال يتعرض لمشكلات عديدة. من هذه المئه

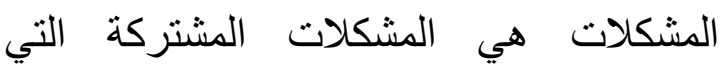
تعرض لها مجال تعليم اللغة العربية للناطقين

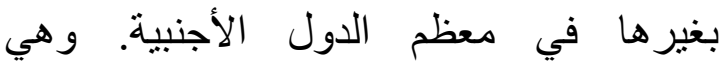
المشكلات الناتجة من الاستناد إلى المنى المناهج

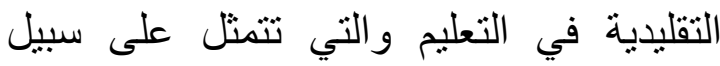
المثال لا الحصر في الافتقار إلى المقررات فئل فلئل

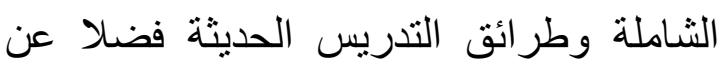
عدم مساندة المعلمين المؤهلين معرفية ومهنية،

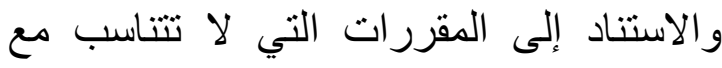

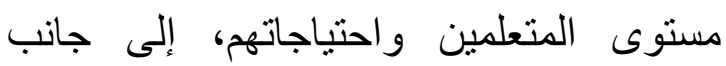

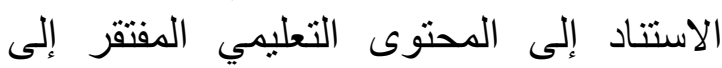

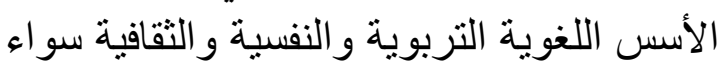
كان في اختياره أو تتظيمه. (أفريجون أفندي، 9: 2013

إلى جانب تعرضه لتلك المشكلات المشتركة الثائعة تعرض مجال تعلئ تعرضه اللغة العربية في إندونيسيا بشكل خاص لمشكلات خاصنة عديدة يمكن ذكر أهمها فيما يلي: أو لا: المشكلة في الاتجاه التعليمي-: تتمثل هذه المشكلة في تعليم اللغة العربية الذي الأي يسعى بصورة بالغة إلى تحقيق الأهداف الدينية ويتقيد باتجاه النحو و الترجمة. يتركز التعليم في
ضوء هذا الاتجاه على عملية تمكين الطلاب من

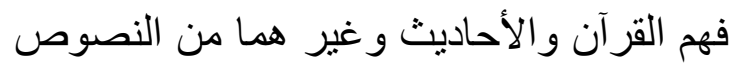
العربية الدينية. وتحقيقا لهذا الهذف الدئ الدينية تهنم عملية التعليم بالإلمام بالقواعد العربية ومهارة

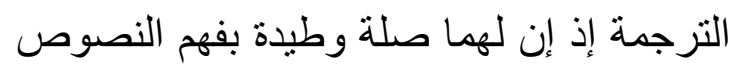

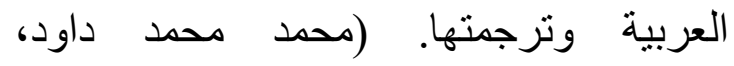
(2019:13

تعليم اللغة العربية وتعلمها من أجل الأهداف

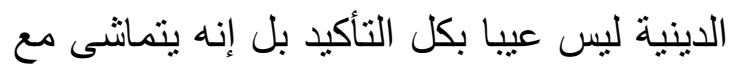
كون هذه اللغة لغة دينية التي ينطق بها القرآن

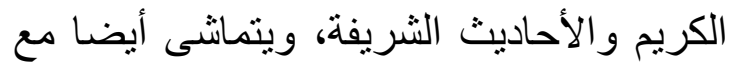

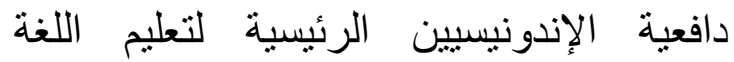
العربية. إلا أن التركيز البالغ على هذا الجانب

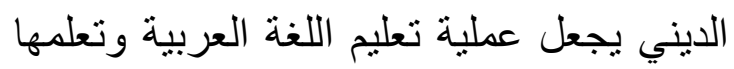

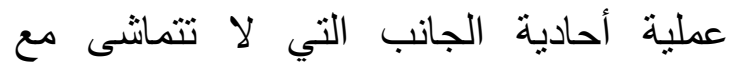
متطلبات مستجدة لتعليم هذه اللغة وتعلمها بوصفها لغة أجنبية، وذلك لأنها تعامل اللغة هذهة العربية بوصفها لغة الدين فقط وتهمل كونها لغة مجالات الحياة الأخرى. (محمد محمد داود، 4: (2019

وتعليم اللغة العربية في ضوء مثل هذا

الاتجاه يؤثر سلبيا على تنوع الخبرات اللغوية

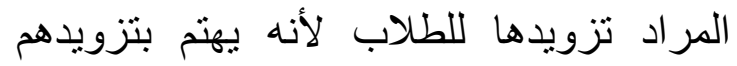

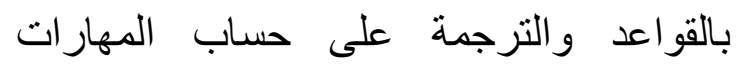
اللغوية الأخرى منثل مهارة الاستماع والكلام

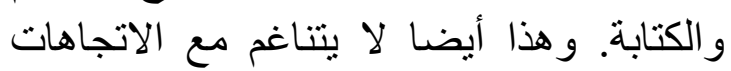

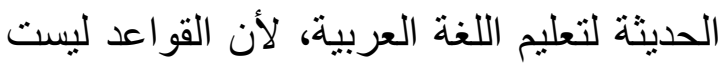

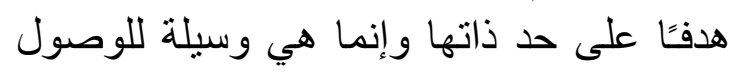

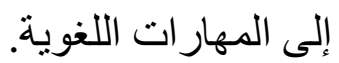

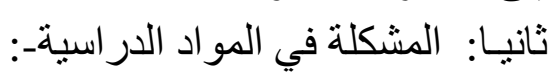
من حيث المواد الدراسية يمكن تصنيف التهواه التهاه تعليم اللغة العربية في إندونيسيا إلى اتجاهين هما: 1 . تعليم اللغة العربية من خلال الكتب اللغوية والدينية، وهذا مما يترتب على الاهتمام البالغ بالجانب الديني في تعليم اللغة العربية. 
تعليم اللغة العربية من خلال سلسلة 2 تعليم اللغة العربية للناطقين بغير ها الصادرة من

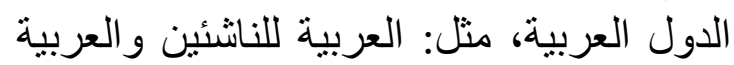
بين بيلك.

هذان الاتجاهان لم يقدما نتيجة مرضية تذكر لمجال تعليم اللغة العربية في إندونيسيا.

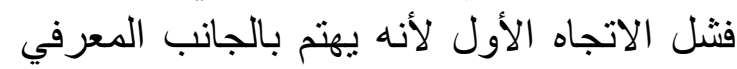

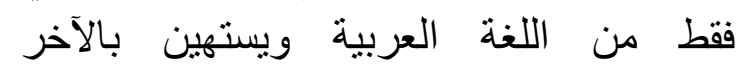
الاتصالي. وفضلا عن ذلك فإن هذا الاتجاه يفتقر إلى المبدأ اللغوي لإبعاده اللغة من وظيفتها

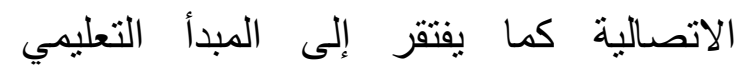
لاستنادها في التعليم إلى الكتب الدينية و اللغوية

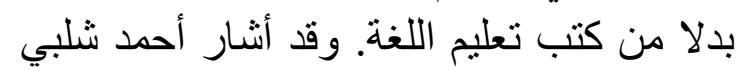
بعد أن مسح مراكز تعليم اللغة العربية بإندونيسيا في السبعينات إلى هذه المشكلة مؤكدا أن من أهم ما يفتقر إليه تعليم اللغة العربية التيات هوه

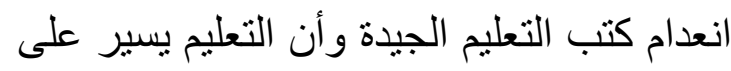

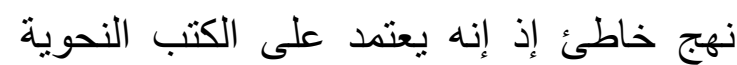

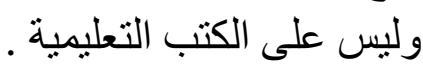
أما الاتجاه الثاني فيرجع المآخذ عليه لعدم مراعاته المحتوى اللغوي الثقافي في التياه

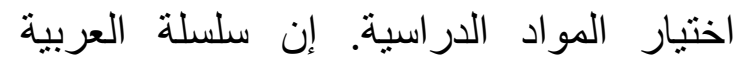
للناشتئين و العربية بين يديك لا يخص إعدادها لادها الإندونيسيين خاصة ولكن الناطقين بغير العربية

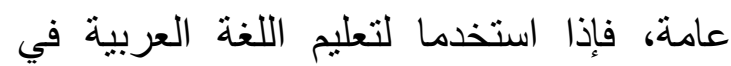

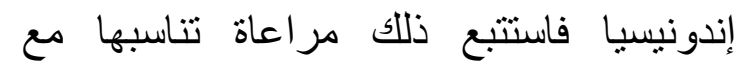
المستوى اللغوي للإندونيسيين كما استتبع إدماج محتوى الثقافة الإندونيسية. ثنالثا: المشكلة في طر ائق التدريس-: إن طريقة التدريس التي شاع استخدامها في في فئي تعليم اللغة العربية في إندونيسيا هي طريقة

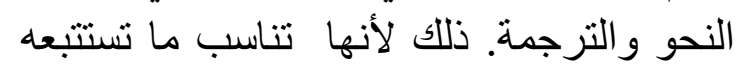

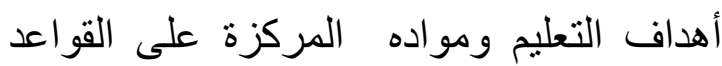

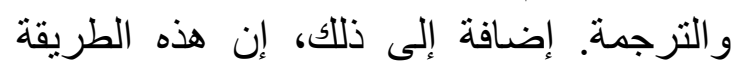
تسمح إلى حد كبير استخدام اللغة الأم في عملية

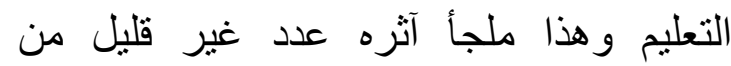

المعلمين في إندونيسيا الذين لا يتمتعون بما يكفي من مهارة التحدث باللغة العربية . لألئ

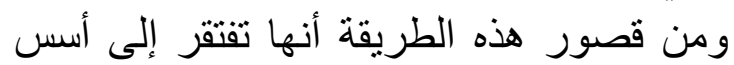

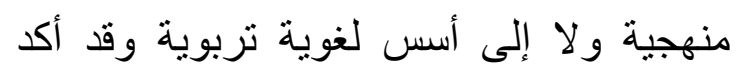
العلماء أنها قد ثبت فثلها في تعليم اللغة العربية بنتيجة مرضية في معظم الدول الأجنبية الناطقة بغير العربية. ونتيجة التعليم على هذه الطريقة

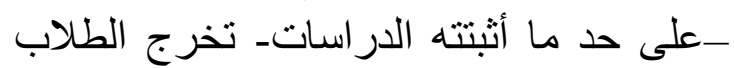
الملمين بقو اعد اللغة العربية وفن الترجمة ولكن التئن مفتقرين إلى مهار ات الاتصال باللغة العربية.

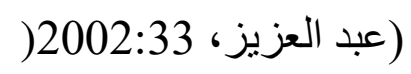
هنالك محاو لات في بعض في استخدام طر ائق

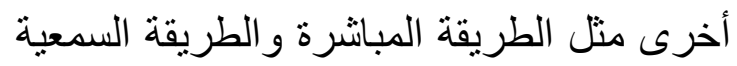

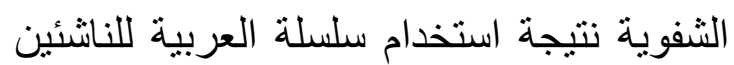

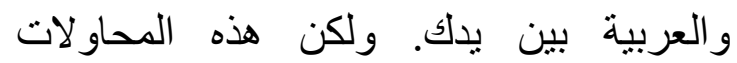
اصطدمت بمستوى المعلمين المتدني في لئي الاتصال الثفوي باللغة العربية.الجامعات التهات رابعا: مشكلة الموارد البشرية -: ومن المشاكل التي تتعلق بمعلمي اللغة العربية في إندونيسيا هي:

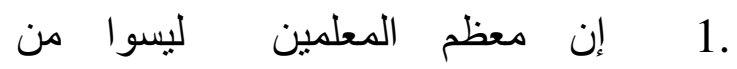
المتخصصين في تعليم اللغة الأجنبية أو العربية

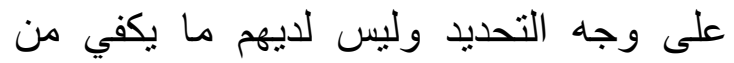
المعلومات حول تعليم اللغة ومنهجها. إنما معظمهم الملمون بقواعد اللغة العربية وترجمة نصوصها أو خريجو جامعات الثرق الأوسط المتخصص في غير العربية.

2 إن معظمهح لم يتلقوا تدريبات إعداد 2.

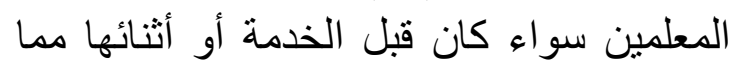
يمنعهم من تحسين أدائهم التعليمي. 3. 3.

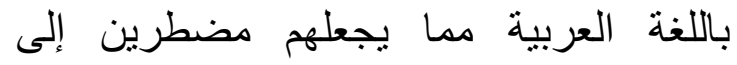

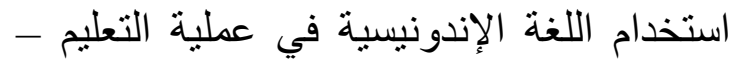
الأمر الذي يقف وراء شيوع استخدام طريقة 
النحو والترجمة في مراكز تعليم اللغة العربية في إندونيسيا. هذه القصور في الموارد البشرية لا يأتي من

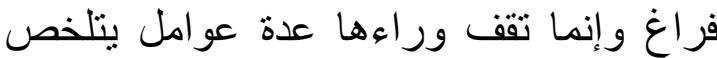
أهمها فيمل بلي:

1 انعدام تخصص تعليم اللغة العربية خاصة على المستوى الماجستير و الدكتور اه مدة طويلة قبل أن ظهر أخيرا في السنوات الأبير والخيرة

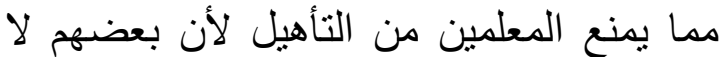

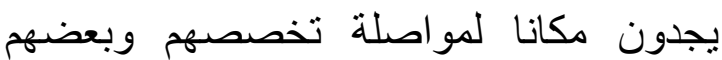
مضطرون إلى التخصص في مجالات العلوم الأخرى التى لا علاقة لها مهنيا ومعرفيا بكونهر معلمي اللغة العربية. ندرة الدورات التدريبية التي يمكن أن 2. يستفيد منها المعلمون في تحسين أدائهم التعليمي.

اتجاه النحو والترجمة السائد في تعليم اللغة العربية. فبما أن هؤلاء المعلمين هم إنتاج هذا الاتجاه التقليدي فلا يدعو للاستغراب إذاء لإناء كانو ا متمكنين من حيث القواه القد ولدو والترجمة وضعفاء في المهارات الاتصالية أو مهارة الكلام على وجه التحديد. وهذا القصور يعد مشكلة شائكة يؤدي إلى مشكلة أخرى أساسية التي لا تقل خطورة وهي

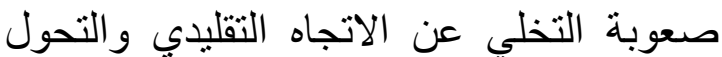
إلى الآخر الحديث، لأن المعلمين أنفسهم إنتاج هذا الاتجاه التقليدي من ناحية ولم يمروا بخبرات يمكن أن تحولهم من هذا الاتجاه من ناحية أخرى. فكيف يتخلون عما يتبنونه؟ أو في المرحلة التطبيقية: كيف يعلمون الطلاب مهارة

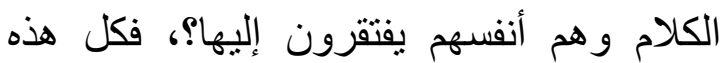

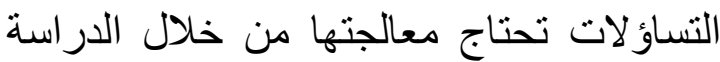

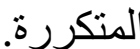

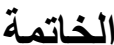

يتضح مما سبق بيانه أن تعليم اللغة العربية يمر

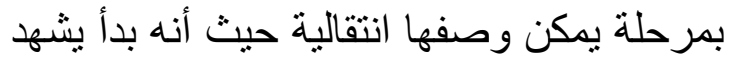
بعض التطورات الملحوظة الواعدة من ناحية، ولا يز ال في الوقت نفسه يتعرض لعدة مشاكل شائكة من ناحية أخرى. على الر غم من القصور

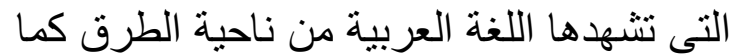
أثرنا إليه سابقاً، إلا أن مجال تعليم اللغة العربية في إندونيسيا شهذ تطور ا ملحوظا وهذا التطور لا من حيث الإدارة فحسب وإنما من حيث

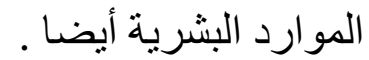
ومن الملاحظة أن التطور ات التي أنجز ها مجال تعليم اللغة العربية في إندونيسيا تغطي جميع جو انب التعليم من منهج و إدارة وموارد بشرية مما يعني أنه قد توافرت لهذا منها المجال شروط

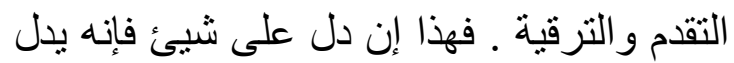

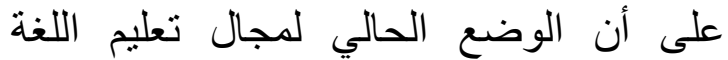

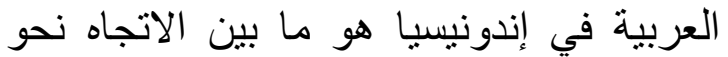

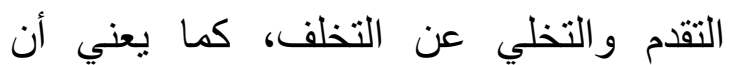
مستقبله اللامع يحدده مدى إنجاز هذا التقدم

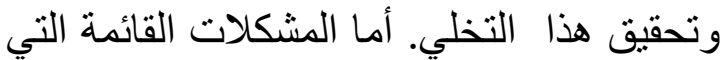

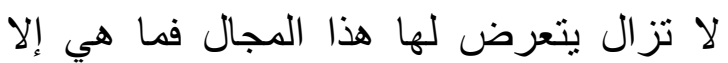
جزء لم تصل إليه هذه التطور ات غير المكتملة، ستزول هذه المشكلات بمشيئة الله تزامنا مع لهاه لهره اكتمال هذه التطورات، وهذا طبعا يتطلب جهودا مستمرة من المعنيين بهذا المجال .

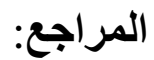

ظواهر اللغة . Afandi, Afrijon. 2013 العربية ومشكلات عملية تعليمها للناطقين بغير ها , Journal of English and Arabic Language Teaching, Volume 4, No. 1 (2013). Pusat Bahasa UIN Suska Riau. أحمد فؤاد أفندي، 2006 ـ منهج تعليم اللغة لئة

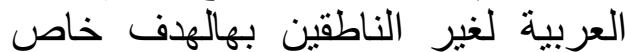
(تجربة مؤسسة تثقيف الأمة بمالانج، 
القرآن لغته وتفسيره، لجنة المؤتمر الدولي القرآن لغته وتفسيره وأولى النهى النهى

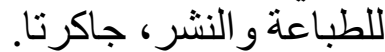

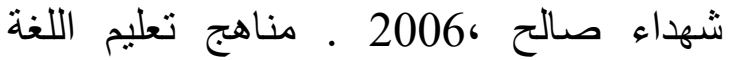
العربية في الددارس الابتدائية بإندونيسيا

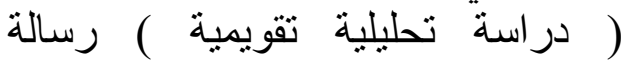
الدكتوراه غير منشورة، جامعة النيلين،

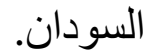

عبد العزيز إبراهيم العصيلي، 2002. طرائق تعليم اللغة العربية للناطقين بلغينة اللغات أخرى، الطبعة الأولى، جامعة للنئة الإمام

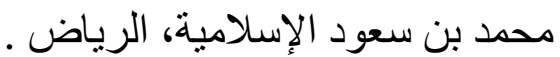

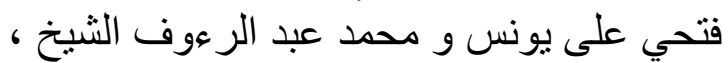
2003. المرجع في تعليم اللغة العربية التئية للأجانب (من النظرية إلى النطبيق)، مكتبة وهبة، القاهرة. الو اقع Maman, Rusman. 2012.

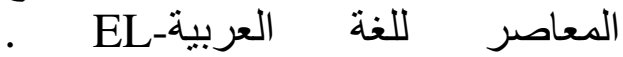
IBTIKAR: Jurnal Pendidikan Bahasa Arab, Volume 1, No. 1 (2012), IAIN Syekh Nurjati Cirebon.

محمد إلهام مختار ، 2018. المشكلات المنهجية في تعليم اللغة العربية للناطقين بغيرها في إندونسيسا (در اسة في المعاهد اللغوية للئية التابعة لمؤسسة مسلمي آسيا الخيرية)،

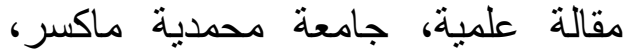

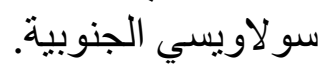

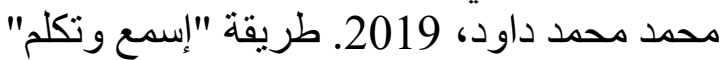
نظرية في بناء القدرة اللغوية لاكتساب

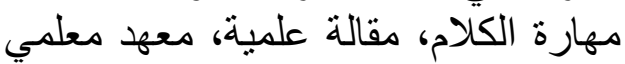

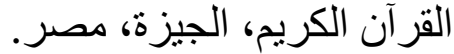
.2019أثر القرآن الكريم

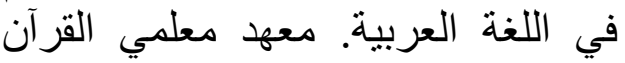
الكريم، مقالة علمية، العمر انية، الجيزة،

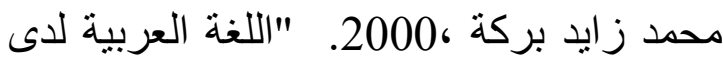
الناطقين بها و الناطقين بغير ها"، المجلة الكئة

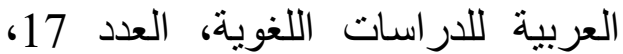
معهد الخرطوم الدولي للغة العربية.
محمد عالي الخولي، 2000. أساليب تذريس اللغة العربية، الطبعة الثانية ، مطابع دار التارئ الفلاح للنشر و التوزيع، الأردن.

Muchtar, M. Contextual Teaching and Learning Method in Studying Arabic. HUNAFA: Jurnal Studia Islamika, Volume 14, No. 1 (2017), 175188.

https://doi.org/https://doi.org/1 0.24239/jsi.v14i1.465.175-188, (diakses, 29 Mei 2020).

نصر الدين إدريس جوهر،2006 ـ تعليم اللغة العربية على الدستوى الجامعي في في لئية إندونيسيا في ضوء تعلية رليم اللغة التعربية للناطقين بغير ها، رسالة الدكتور اهنياه غير النير منشورة، جامعة النيلين، السودان.

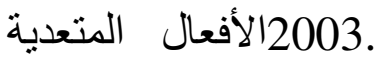

بحروف الجر وتدريسها للإندونيسيين،

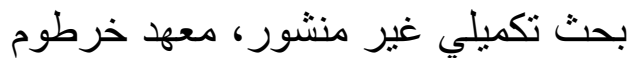
الدولي للغة العربية، السودان. رشدي أحمد طعيمة، 1989. تعليم اللغة العربية لئرية

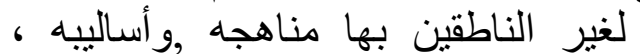
منشورات المنظمة الإسلامية للتربية و العلوم و الثقافة، الرباط. 